\title{
Appraisal of Nature of Capacity Building Programs of HIV/AIDS Supply Chain Workforce in Nigeria
}

\author{
Sunday O Aguora ${ }^{1 *}$, Azuka C Oparah ${ }^{2}$, Edith C Okechukwu ${ }^{1}$, Jeffrey S Soni ${ }^{2}$ \\ ${ }^{1}$ School of Public Health, Texila American University, Georgetown, Guyana, South America \\ ${ }^{2}$ Department of Pharmacy and Pharmacy Practice, Faculty of Pharmacy, University of \\ Benin, Benin City, Nigeria
}

\begin{abstract}
This study on appraisal of nature of capacity building programs of HIV/AIDS supply chain workforce in Nigeria involved cross-sectional observational design. A pre-tested self-completion structured questionnaire was administered to 422 participants drawn from HIV/AIDS supply chain workforce. The survey had a response rate of 396(93.8\%). The reliability statistics showed the questionnaire is reliable for nature of capacity building programs, Cronbach alpha $(\alpha=0.886)$. Onthe-job training was the most predominant capacity building approach, while task shifting and fellowship program were the least used. The study revealed nature of capacity building of HIVIAIDS supply chain workforce comprised of on-the-job training, short courses, residential training, fieldbased, work-based, in-service, pre-service and e-learning trainings as leading strategies and excellent in strengthening HIV/AIDS supply chain workforce capacity, mean \pm standard deviation score (3.774 \pm 0.9882) on a Likert scale of 1-5 (5-point scale). Others included collaboration, university-based model, mentorship, task shifting and fellowship program. Inferential statistics revealed that Managers and Directors with postgraduate qualification have more benefit from the capacity building programs $(p<0.05)$. Whilst age, sex and years of experience have no effect on the capacity building programs of HIV/AIDS supply chain workforce $(p>0.05)$. Chi-square statistic revealed that nature of capacity building program is a significant factor of HIV/AIDS supply chain workforce capacity $(p<0.05)$. Effective capacity building programs are central to the improvement of HIV/AIDS supply chain systems and responsiveness.
\end{abstract}

Keywords: Capacity building, HIV/AIDS, supply chain, workforce.

\section{Introduction}

The importance of building the capacity of workforce as part of strengthening health systems and ensuring sustainability cannot be overemphasized [1]. Workforce capacity can be developed through formal and informal programs to ensure availability of skills to provide quality health services [2]. Recognizable approaches for capacity development in supply chain management to ensure availability of skilled workforce include; pre-service, in-service, residential, onsite, fieldbased, work-based, on-the-job, distance learning, e-learning, mentorship, short courses, task shifting, face-to-face learning, blended learning, fellowship program, outsourcing, establishing logistics management units (LMUs), developing incentives, creating accreditation and strengthening policy $[3,4,5$, $6,7,8,9]$.

Some of the vital impacts of capacity building programs in Nigeria and other countries include; long-term availability of skills in-country crucial for success and sustainability of HIV/AIDS program in Nigeria [5]; improved access to safe, effective and quality-assured medicines for the treatment of HIV/AIDS, Tuberculosis and Malaria in the East African region [10]; enhanced workforce skills, health system performance and evidencebase for policies, programs and practice resulting in better control of communicable diseases in Australia [3]; boosted leadership and management capacity for HIV/AIDS program in Zimbabwe, Ethiopia, Iran, Egypt, Liberia and Uganda $[2,11,12,13,14,15,16$, 17]; better skills in pharmaceutical supply 
management in East Africa [18]; health facility management skills essential for long-term health systems strengthening in Liberia [17] and advanced institutional and workforce capacity to provide quality health services [2].

Nigeria's health sector has particularly experienced a number of other lingering crises in recent times [19, 20]. It has been reported that lack of adequate health workforce in Nigeria to potentially meet increased demand have also contributed to non-implementation of National Health Insurance Scheme (NHIS) at the state and local government levels [21]. Other actions that might be required to strengthen the supply chain workforce may be implemented as part of broader health workforce policies and include improving public sector pay and incentives [22]; creating rural pipelines to education and training to ease education and deployment in under-served areas [23]; improving education strategies to adapt content and modalities of training to current and emerging health system needs [24] and more delegation of tasks to cadres with shorter training [25].

While capacity building has been well developed in the private or for-profit business sector, it remains less well-defined in the public, non-profit and social sectors in low- and middle-income countries [1]. Often capacity building has resulted in disempowerment of local organizations rather than promoting local ownership and sustainability [1]. This study unlike others will strengthen existing literature on workforce capacity development and reduce the gap in knowledge applying to HIV/AIDS supply chain workforce. It will help the Federal and State Ministries of Health to determine a procedure for strengthening human resources in health supply chains.

In spite of the huge expenditure of millions of dollars, there have not been rigorous evaluations of capacity building efforts [1]. It is important that a firm evidence-base should be established concerning strategies that work and what doesn't work to build capacity before additional investments are made [1]. This will ensure that each country is better equipped to adopt and adapt the lessons learned from every other nation and shared learning would be greatly assisted by a global repository of evidence on health system performance [26]. This type of evidence is a global public good.
Therefore, it is important to first conduct health system assessments, analyze challenges to health system strengthening success, prioritize addressing challenges, and implement appropriate activities to build new capacity in overcoming challenges.

Therefore, the present study seeks to assess nature of capacity building programs of HIV/AIDS supply chain workforce in Nigeria.

\section{Methods}

\section{Selection of the Area}

This study was conducted in Abuja, the administrative centre of Nigeria. Abuja has six Area Councils and common boundary to the north with Kaduna State, to the west with Niger State, to east and south-east with Nassarawa State and to the south-west with Kogi State [27]. Abuja is a city ("Centre of Unity") and became the capital of Nigeria on December 12, 1991. Most of the HIV/AIDS organizations have their offices in Abuja from where they carry out their supply chain functions around the country.

\section{Sample Size Determination}

The representative sample size for the infinite population was calculated using Cochran's formula $\left(\mathrm{n}_{0}=\mathrm{z}^{2} \mathrm{pq} / \mathrm{e}^{2}\right)$ [28].

$\mathrm{n}_{0}=$ sample size

$\mathrm{z}=1.96$ (selected critical value of desired confidence level)

$\mathrm{p}=0.5$ (assuming the maximum variability, which is equal to $50 \%$ )

$$
q=1-\mathrm{p}
$$

$\mathrm{e}=0.05( \pm 5 \%$ desired level of precision at $95 \%$ confidence level)

$\mathrm{n}_{0}=(1.96)^{2}(0.5)(0.5) /(0.05)^{2}$

$\mathrm{n}_{0}=384.16$

To the calculated sample size, $10 \%$ overage was added to provide for drop out, nonresponse, incomplete response and late response. This ensured minimum response rate for the study.

\section{Sampling Technique}

HIV/AIDS supply chain workforce (422) from public sector, private sector, nongovernmental organization, faith-based organization and donor agency, minimum of bachelor's degree qualification and two (2) years in their organization, signed consent form and not a participant in the pilot without gender 
discrimination were selected using random sampling technique. The study excluded other supply chain workforce, HIV/AIDS supply chain workforce less than two (2) years in their organization, without at least bachelor's degree qualification, those that participated in pilot and declined to sign consent form.

\section{Data Collection}

Cross-sectional observational design was employed and comprised of two sources of data, namely primary and secondary sources of data. The primary sources of data were those collected from the field through a selfcompletion structured questionnaire. Secondary data were from published literature sources. The purpose of the study and questionnaire were explained to the participants. Participants read and signed the consent form before joining the study. Participants were informed they could withdraw at any point from the study without consequences. Identity of participants was kept anonymous and confidential by excluding all identifiers. The questionnaire had twenty (20) questions with which relevant information in the area of socio-demographic characteristics and nature of capacity building programs of HIV/AIDS supply chain workforce were obtained. The questionnaire was pretested with volunteers similar to expected participants to ascertain its effectiveness and suitability. Pre-testing of the questionnaire was done with 38 participants $(10 \%$ of the calculated sample size). After the pretest, amendments were made in the light of lessons learned.

The questionnaire required about fifteen (15) minutes to complete. Construct validity was ensured by fashioning the questionnaire based on relevant literatures and empirical studies. Content validity was ensured by modifying the questionnaire based on the results of the supervisor's review and pre-test. Social response bias was safeguarded as participants were allowed to complete and return the questionnaire on a later date, and not necessarily in the presence of the researcher. Ethical approval to carry out the study was granted by National Health Research Ethics Committee of Nigeria (NHREC).

\section{Data Analysis}

Data obtained were coded and analyzed using Statistical Package for Social Sciences (SPSS) version 22 (SPSS Inc., Chicago, Illinois, USA) for descriptive statistics. Items within each domain were summarized using descriptive statistics such as mean and standard deviation. Two-sided independent student's ttest and one-way analysis of variance (ANOVA) were used to compare means across groups with the aid of GraphPad Instant version 3 for inferential statistics, P-values set at $\mathrm{p}<0.05$. The negative response was $<2.5$ while positive response was $>2.5$. Chi-square statistic was used to determine the level of relationship at $5 \%$ level of significance ( $\mathrm{p} \leq 0.05)$.

\section{Results and Discussion}

The survey had a response rate of 396 (93.8\%). Table (1) socio-demographic characteristics, with most of the participants $328(82.9 \%)$ between the age 30 and 49 years. More of male participants 275 (69.4\%) and participant's years of experience in HIV/AIDS supply chain $345(87.1 \%)$ between 4 and 15 years. Majority $294(74.2 \%)$ in the rank of manager, supervisor, specialist, advisor and officer. More than half $221(55.8 \%)$ had a master's degree. Table (2) percentage frequency of nature of capacity building programs, Table (3) reliability analysis of nature of capacity building programs, Table (4) effect of socio-demographic characteristics on nature of capacity building programs and Table (5) Chi-square tests.

The participants have substantial experience with good understanding of capacity building strategies of HIV/AIDS supply chain workforce, and their opinion can be trusted for quality research outcomes. The respondents have an attained ample level of skill with over half of them with master's degree qualification and played key roles in strengthening capacity of HIV/AIDS supply chain workforce. They have practical knowledge of effective capacity building strategies and basic background required for supply chain functions.

The study revealed that on-the-job training is the predominant strategy in HIV/AIDS supply 
chain workforce capacity building programs. This is followed by short courses and jointly residential, field-based, work-based, in-service, pre-service and e-learning trainings. Collaboration among stakeholders, universitybased model and mentorship on real work situation and task shifting are in less use while fellowship training program seemed the least used strategy. The outcome of the present study suggests that the various capacity building strategies can be a useful model for strengthening human resources in HIV/AIDS supply chain for improved health service delivery and agrees with previously reported approaches for capacity development in supply chain management [4]. This is in addition to outsourcing, establishing logistics management units (LMUs), developing incentives, creating accreditation and strengthening policy [4]. Similar approaches have been used to strengthen health workforce capacity in other countries including The Gambia, Nicaragua and Liberia [2]. It is worth noting that some capacity building strategies have been implemented to ensure long-term availability of skills in different countries with positive results such as, on-site and off-site training in South Africa [29], collaboration among stakeholders in Uganda, Kenya, Tanzania and Rwanda [18], on-the-job training and short courses in Uganda, Kenya, Tanzania and Rwanda [10], mentorship on real work situation in Uganda [30], field-based training in Australia [3], skills transfer in Liberia [17], fellowship training program in Uganda [2], work-based/ hands-on training in Uganda [2], in-service, pre-service and e-learning training in Nigeria [5]. Furthermore, it has been reported that fellowship program does not yield quick returns but are critical in building longer-term capacities needed to address HIV/AIDS in coming generations [31].

The study further agreed with previous studies $[10,14]$ that skill building approaches/activities that do not take workers away from their places of work for long periods such as on-the-job training and short courses/incountry workshops with regular follow-up were effective and preferred modes of capacity building in Iran and East African countries, respectively. Effective capacity building program will guarantee improved capacity of workforces to ensure a reliable supply chain for HIV/AIDS program [32]. Workforces plays a vital role in supply chain management, thus improving their capacities would result in improved quality of HIV/AIDS services. It can be assumed that appropriate capacity building strategy equips workforce with skills that make them more efficient and productive. Welltrained supply chain workforce often has higher motivation and morale leading to lower turnover rates, more confident as well as aware of the expectations and work better than teams, more likely to accept change and take initiatives [33]. Skilled workforce is equipped to train other employees, thus reduces pressure on the management team. Similarly, it has been suggested that training is not a panacea and lack of frequent training is not necessarily the cause of under-performance, as the problem may not be the type solved by training [34].

The mean \pm standard deviation score $(3.774$ \pm 0.9882 ) for the nature of capacity building programs indicates that existing methods are excellent in strengthening workforce capacity. Factor loading (0.674-0.968) is good and entails all mean components are added to the summation. Cronbach's alpha, $\alpha=0.886$ showed the questionnaire is reliable.

Inferential statistics revealed that sociodemographic characteristics such as educational qualification and job title/rank have an effect on the nature of capacity building programs $(\mathrm{P}<0.05)$. Those in the rank of Managers and Directors with postgraduate qualification have more benefit from the capacity building programs. However, age, sex and years of experience have no effect on the capacity building programs of HIV/AIDS supply chain workforce.

Chi-square statistic was carried out to determine the level of relationship at 5\% level of significance $(\mathrm{P}<0.05)$ and there is a relationship between nature of capacity building programs and HIV/AIDS supply chain workforce capacity. It revealed that nature of capacity building programs is a significant factor of HIV/AIDS supply chain workforce capacity. 
Table 1. Socio-demographic Characteristics of HIV/AIDS Supply Chain Workforce (N=396)

\begin{tabular}{|c|c|c|}
\hline Socio-demographic Characteristics & Categorization & Number $(\%)$ \\
\hline \multirow{5}{*}{ Age (Years) } & $30-39$ & $121(30.6)$ \\
\hline & $40-49$ & $207(52.3)$ \\
\hline & $50-59$ & $52(13.1)$ \\
\hline & $\geq 60$ & $16(4.0)$ \\
\hline & Total & $396(100.0)$ \\
\hline \multirow[t]{3}{*}{ Gender } & Female & $121(30.6)$ \\
\hline & Male & $275(69.4)$ \\
\hline & Total & $396(100.0)$ \\
\hline \multirow[t]{6}{*}{ Years of Experience (years) } & $0-3$ & $34(8.6)$ \\
\hline & $4-7$ & $104(26.3)$ \\
\hline & $8-11$ & $138(34.8)$ \\
\hline & $12-15$ & $103(26.0)$ \\
\hline & $\geq 16$ & $17(4.3)$ \\
\hline & Total & $396(100.0)$ \\
\hline \multirow[t]{5}{*}{ Job Title } & Director & $68(17.2)$ \\
\hline & Associate/Assistant Director & $34(8.6)$ \\
\hline & Manager/Supervisor & $156(39.4)$ \\
\hline & Specialist/Advisor/Officer & $138(34.8)$ \\
\hline & Total & $396(100.0)$ \\
\hline \multirow[t]{6}{*}{ Highest Educational Qualification } & Bachelor's Degree & $119(30.1)$ \\
\hline & Postgraduate Diploma & $14(3.5)$ \\
\hline & Fellowship & $35(8.8)$ \\
\hline & Master's Degree & $221(55.8)$ \\
\hline & Doctorate & $7(1.8)$ \\
\hline & Total & $396(100.0)$ \\
\hline
\end{tabular}

Table 2. Percentage Frequency of Nature of Capacity Building Programs of HIV/AIDS Supply Chain Workforce $(\mathrm{N}=396)$

\begin{tabular}{|c|c|}
\hline \multirow[t]{2}{*}{ Items } & Positive Responses \\
\hline & Frequency N (\%) \\
\hline \multicolumn{2}{|c|}{$\begin{array}{l}\text { Capacity building strategies being used in Nigeria HIV/AIDS supply chain } \\
\text { to ensure availability of skilled workforce to provide quality health services }\end{array}$} \\
\hline Residential training & $327(82.6)$ \\
\hline Fellowship training & $190(48.0)$ \\
\hline Mentorship on real work situation & $276(69.7)$ \\
\hline Field-based training & $327(82.6)$ \\
\hline Work-based training & $327(82.6)$ \\
\hline On-the-job training & $396(100.0)$ \\
\hline Short courses & $362(91.4)$ \\
\hline University-based model & $293(74.0)$ \\
\hline In-service training & $327(82.6)$ \\
\hline Pre-service training & $327(82.6)$ \\
\hline E-learning training & $328(82.8)$ \\
\hline Task shifting & $258(65.2)$ \\
\hline Collaboration among stakeholders & $310(78.3)$ \\
\hline
\end{tabular}

Positive responses $=$ Agree/ Strongly Agree 
Table 3. Reliability Analysis of Nature of Capacity Building Programs of HIV/AIDS Supply Chain Workforce $(\mathrm{N}=396)$

\begin{tabular}{|l|l|l|l|l|l|}
\hline Items & Mean & SD & Factor Loading & Cronbach's Alpha \\
\hline $\begin{array}{l}\text { Capacity building strategies being } \\
\text { availability of skilled workforce to provide quality health services }\end{array}$ \\
\hline Residential training & 3.833 & 0.9613 & 0.674 & $\mathbf{0 . 8 8 6}$ \\
\hline Fellowship training & 3.104 & 1.2855 & 0.783 & \\
\hline Mentorship on real work situation & 3.793 & 1.2478 & 0.865 & \\
\hline Field-based training & 3.747 & 1.0296 & 0.922 & \\
\hline Work-based training & 3.747 & 1.0296 & 0.922 & \\
\hline On-the-job training & 4.306 & 0.4612 & 0.837 & \\
\hline Short courses & 4.003 & 0.7204 & 0.911 & \\
\hline University-based model & 3.576 & 1.0963 & 0.878 & \\
\hline In-service training & 3.833 & 0.9154 & 0.968 & \\
\hline Pre-service training & 3.879 & 0.9469 & 0.965 & \\
\hline E-learning training & 3.967 & 0.9995 & 0.933 & \\
\hline Task shifting & 3.487 & 1.1351 & 0.848 & \\
\hline Collaboration among stakeholders & 3.790 & 1.0183 & 0.888 & \\
\hline Mean of mean \pm SD & $\mathbf{3 . 7 7 4}$ & $\mathbf{0 . 9 8 8 2}$ & & \\
\hline
\end{tabular}

Table 4. Effect of Socio-demographic Characteristics on Nature of Capacity Building Programs of HIV/AIDS Supply Chain Workforce $(\mathrm{N}=396)$

\begin{tabular}{|l|l|l|}
\hline Variables & N & Nature of Capacity Building \\
\hline Age & 121 & $3.704 \pm 0.9816$ \\
\hline Below 40 & 275 & $3.778 \pm 0.9561$ \\
\hline Above 40 & 0.4861 \\
\hline P-value & \multicolumn{2}{|l|}{} \\
\hline Sex & 275 & $3.768 \pm 0.9560$ \\
\hline Male & 121 & $3.728 \pm 0.9865$ \\
\hline Female & \multicolumn{2}{|l|}{0.7043} \\
\hline P-value & 138 & $3.683 \pm 0.9846$ \\
\hline Years of experience & 258 & $3.795 \pm 0.9517$ \\
\hline Below 8 & \multicolumn{2}{|l|}{0.2709} \\
\hline Above 8 & 119 & $3.671 \pm 0.6700$ \\
\hline P-value & 277 & $3.792 \pm 0.6301$ \\
\hline Highest Education & \multicolumn{2}{|l|}{} \\
\hline Bachelor's Degree & \multicolumn{2}{|l|}{} \\
\hline Postgraduate & \multicolumn{2}{|l|}{} \\
\hline P-value & $3.774 \pm 0.9556$ \\
\hline Job Titles & 138 & $3.522 \pm 0.9829$ \\
\hline Managers/Directors & 258 & $\mathbf{0 . 0 1 7 9}$ \\
\hline Specialists/Advisors & 138 \\
\hline P-value & &
\end{tabular}

Table 5. Relationship between Nature of Capacity Building Programs and HIV/AIDS Supply Chain Workforce Capacity $(\mathrm{N}=396)$

\begin{tabular}{|l|l|l|l|l|l|}
\hline $\begin{array}{l}\text { Nature of Capacity } \\
\text { Building Programs }\end{array}$ & Factors of Supply Chain Workforce Capacity & Total & $\chi^{2}$ & p-value \\
\cline { 2 - 5 } $\begin{array}{l}\text { Good Capacity } \\
\text { Building }\end{array}$ & $199(92.1)$ & $17(7.9)$ & $216(100.0)$ & 206 & 0.001 \\
\cline { 1 - 4 } $\begin{array}{l}\text { Poor Capacity } \\
\text { Building }\end{array}$ & $38(21.1)$ & $142(78.9)$ & $180(100.0)$ & \\
\hline
\end{tabular}




\section{Null Hypothesis (Ho)}

Nature of capacity building programs is not a significant factor of HIV/AIDS supply chain workforce capacity.

\section{Alternative Hypothesis (Ha)}

Nature of capacity building programs is a significant factor of HIV/AIDS supply chain workforce capacity.

\section{Conclusion}

The study revealed that nature of capacity building programs to improve capacity of HIV/AIDS supply chain workforce include onthe-job training, short courses, residential training, field-based, work-based, in-service, pre-service and e-learning trainings as leading strategies. Other strategies include

\section{References}

[1] Goldberg, J. and Bryant, M. (2012). Country ownership and capacity building: the next buzzwords in health systems strengthening or a truly new approach to development? BMC Public Health, 12:531-539.

[2] Matovu, J. K. B., Rhoda, K., Wanyenze, Susan Mawemuko, Olico Okui, William Bazeyo and David Serwadda (2013). Strengthening health workforce capacity through work-based training; $B M C$ International Health and Human Rights, 13:8.

[3] Patel, M. S. and Phillips, C. (2009). Strengthening field-based training in low and middle-income countries to build to build public health capacity: Lessons from Australia's Master of Applied Epidemiology program. Aust New Zeal Health Pol, 6:5. doi: 10.1186/1743-8462-6-5.

[4] Brossette, V., Silve, B., Grall, A., Bardy, K., Pilz, K., Dicko, M., and Gerberg, L. (2011). Workforce Excellence in Health Supply Chain Management: Literature Review, 1-21.

[5] Adekola, A. and Adelanwa, A. (2014). Developing the SCM workforce in Nigeria through contextualized preservice education and continued professional development. Journal of Pharmaceutical Policy and Practice, 7(Suppl 1): O22.

[6] Brown, A. and Sankaranarayanan, A. (2014). Human Resource Development in Supply Chain Management of Health Commodities - A realist review of UN sources, ISBN: ISBN: 978-1-74088410-5. 10.13140/RG.2.1.2365.1046. collaboration, university-based model, mentorship, task shifting and fellowship program. The strategies are believed to be cost effective, with minimal disruption, and can lead to practice change.

\section{Recommendations}

Federal and State Ministries of Health should ensure implementation of effective capacity building programs as they are central to the improvement of HIV/AIDS supply chain systems and responsiveness. Capacity building should be integrated with strengthening organizational structures, policies and processes that guide and drive supply chain services and essential research including funding, national and international partnerships.

[7] Kattoua, T., Al-Lozi, M. and Alrowwad, A. (2016). A Review of Literature on E-Learning Systems in Higher Education. International Journal of Business Management and Economic Research (IJBMER), 7(5):754-762.

[8] Ahadi, S. and Jacobs, R. L. (2017). A Review of the Literature on Structured On-the-Job Training and Directions for Future Research. Human Resource Development Review, 16(4):323-349.

[9] Nortvig, A. M., Petersen, A. K., and Balle, S. H. (2018). A Literature Review of the Factors Influencing E-Learning and Blended Learning in Relation to Learning Outcome, Student Satisfaction and Engagement. The Electronic Journal of $e$ Learning, 16(1):46-55.

[10]Waako, P., Odoi, R.., Obua, C., Owino, E., Tumwikirize, W., Ogwal-Okeng, J., Anokbonggo, W., Matowe, L., and Aupont, O. (2009). Existing capacity to manage pharmaceuticals and related commodities in East Africa: An assessment with specific reference to antiretroviral therapy, Human Resources for Health 7(1):21 DOI: 10.1186/14784491-7-21.

[11]Feldman, M. D., Huang, L., Guglielmo, B. J., Jordan, R., Kahn, J., Creasman, J. M., WienerKronish, J. P., Lee, K. A., Tehrani, A., Yaffe, K., and Brown, J. S. (2009). Training the next generation of research mentors: The University of Calfornia, San Francisco, Clinical \& Translational Science Institute Mentor Development Program. Clin. Transl. Sci. 2(3):216-221.

[12] Jones, D. S., Tshimanga, M., Worlk, G., Nsubuga, P., Sunderland, N. L., Hader, S. L., and St 
Louis, M. E. (2009). Increasing leadership capacity for HIV/ AIDS programs by strengthening public health epidemiology and management training in Zimbabwe. Hum Res Health, 7:69. doi:10.1186/1478-4491-7-69.

[13] McNabb, M. E., Hiner, C. A., Pfitzer, A., Abduljewad, Y., Nadew, M., Faltamo, P. and Anderson, J. (2009). Tracking working status of HIV/AIDS trained service providers by means of a training information monitoring system in Ethiopia. Hum Res Health, 7:29. doi:10.1186/1478-4491-7-29. [14] Omar, M., Tarin, E., Ashjael, K., Mirzoev, T. and Sheikh, M. R. (2007). In-country capacity development of a training institute: an Iranian experience. Journal of Health Organization Management, 21(6):519-532.

[15] Mansour, M., Mansour, J. B. and El Swesy, A. H. (2010). Scaling up proven public health interventions through a locally owned and sustained leadership development program in rural Upper Egypt. Hum Res Health, 8:1-5.

[16] Mukanga, D., Namusisi, O., Gitta, S. N., Pariyo, G., Tshimanga, M., Weaver, A. and Trostle, M. (2010). Field epidemiology training programs in Africa - where are the graduates? Hum Res Health, 8:18. doi: 10.1186/1478-4491-8-18.

[17] Rowe, L. A., Brillant, S. B., Cleveland, E., Dahn, B. T., Ramanadhan, S., Podesta, M. and Bradley, E. H. (2010). Building capacity in health facility management: guiding principles for skills transfer in Liberia. Human Resources for Health, 8:5. doi: 10.1186/1478-4491-8-5.

[18] Matowe, L., Waako, P., Odoi-adome, R., Kibwage, I., Minzi, O. and Bienvenu, E. (2008). A strategy to improve skills in pharmaceutical supply management in East Africa: the regional technical resource collaboration for pharmaceutical management. Human Resources for Health, 6:30. doi:10.1186/1478-4491-6-30.

[19]WHO (2016): Nigeria. In: Global Health Workforce Alliance. Geneva, Switzerland.

[20] Adeloye, D., David, R. A., Olaogun, A. A., Auta, A., Adesokan, A., Gadanya, M., Opele, J. K., Owagbemi, O., and Iseolorunkanmi, A. (2017). Health workforce and governance: the crisis in Nigeria, Human Resources for Health, 15:32 DOI 10.1186/s12960-017-0205-4.

[21] Okebukola, P. O. and Brieger, W. R. (2016). Providing universal health insurance coverage in Nigeria. Int Q Community Health Educ., 36(4):241246.

[22] McCoy D, Bennett S, Witter S, Pond B, Baker B, Gow J, Chand S, Ensor T, McPake B. (2008).
Salaries and incomes of health workers in subSaharan Africa. Lancet, 371(9613):675-681.

[23] Dolea, C., Stormont, L. and Braichet, J. (2010). Evaluated strategies to increase attraction and retention of health workers in remote and rural areas. Bull World Health Organ, 88(5):379-385.

[24]Frenk, J., Bhutta, Z. A., Chen, L. C., Cohen, J., Crisp, N., Evans, T., Fineberg, H. V. Garcia, P., Ke, Y., Kelley, P., Kistnasamy, B., Meleis, A., Naylor, D., Pablos-Mendez, A., Reddy, S., Scrimshaw, S., Sepulveda, J., Serwadda, D., Zurayk, H. (2010). Health professionals for a new century: transforming education to strengthen health systems in an interdependent world. The Lancet Commissions, 376 (9756):1923-1958.

[25]Foster, N. and McIntyre D. (2012). Economic evaluation of task-shifting approaches to the dispensing of anti-retroviral therapy. Hum Resour Health, 10(1):32.

[26] Reich MR, Takemi K, Roberts MJ, Hsiao WC. (2008). Global action on health systems: A proposal for the Toyako G8 summit. Lancet 371:865-869.

[27]Ebele, F.U., Aregbosola, B.G., Hasstrup, D.T. and Adams, E. (2014). The Effect of Climate Change on Agricultural Production among Farmers in Kwali Area Council of Federal Capital Territory of Nigeria. Advances in Social Sciences Research Journal, 1(2):13-26.

[28] Cochran, W.G. (1977). Sampling Techniques. 3rd Edition, John Wiley \& Sons, New York.

[29] Bergh, A. M., Van Rooyen, E. and Pattinson, R. C. (2008). Scaling up kangaroo mother care in South Africa: 'on-site versus 'off-site' educational facilitation. Hum Resour Health, 6: 13.doi: 10.11186/1478-4491-6-13.

[30] Starcevich, M. M. (2009). Coach mentor: is there a difference? CEO Center for Coaching and Mentoring, Inc. Available from: http://www.coachingandmentoring.com/Articles/me ntoring.html (accessed 13 December 2019).

[31] IOM (Institute of Medicine) (2011). Preparing for the Future of HIV/ AIDS in Africa: A Shared Responsibility. Washington, DC: The National Academies Press.

[32] IOM (Institute of Medicine). (2013). Evaluation of PEPFAR. Washington, DC: The National Academies Press.

[33] Devins, D., Johnson, S. and Sutherland J. (2012). Employee training benefits to small businesses. Journal of Small Business and Enterprise Development, 11: 4.

[34]Daniels, S. (2010). Employee training: a strategic approach to better return on investment. Journal of Business Strategy, 24(5):39-42. 